\title{
Evaluating Unscheduled Readmission to Emergency Department in the Early Period
}

\author{
Abdullah Cüneyt Hocagil ${ }^{1}$, Fikret Bildik ${ }^{2}$, İsa Kılıçaslan², Hilal Hocagil ${ }^{1}$, Hasan Karabulut ${ }^{2}$, \\ Ayfer Keleş², Ahmet Demircan ${ }^{2}$
}

${ }^{1}$ Department of Emergency Medicine, Bülent Ecevit University Faculty of Medicine, Zonguldak, Turkey

${ }^{2}$ Department of Emergency, Gazi University Faculty of Medicine, Ankara, Turkey

Background: The readmission in the early period (RAEP) is defined as the admission of a patient to emergency department (ED) for the second time within 72 hours after discharge from the ED.

Aims: The aim of this study was to determine the disease, patient, doctor, and system related causes of RAEP.

Study Design: Descriptive study.

Methods: This study is a two-stage study that was conducted at Department of Emergency, Gazi University Faculty of Medicine. The causes of RAEP were defined as disease, patient, doctor, and system related causes.

Results: A total of 46,800 adult patients admitted to ED during the study period and $779(1.66 \%)$ patients re- quired RAEP. After the exclusion criteria, 429 of these patients were included the study. The most common reasons for RAEP were renal colic in $46(10.7 \%)$ patients. It was detected that $60.4 \%$ of the causes of RAEP were related to disease, $20.0 \%$ were related to the doctor, $12.1 \%$ were related to the patient, and $7.5 \%$ were related to the hospital management system.

Conclusion: This study revealed that there are patient-, doctor-, and system-related preventable reasons for RAEP and the patients requiring RAEP constitute the high risk group.

Keywords: Early period, emergency department, readmission
The readmission of patients to the emergency department (ED) within 72 hours after discharge from the ED is accepted as readmission in the early period (RAEP) (1). These patients that require RAEP are defined as high-risk groups (2). Although most cases originate mainly from the factors related to the disease, patient and the hospital management systems instead of malpractice, some cases can be prevented. However, the actual causes of RAEP could not be fully elucidated. Therefore, there is a need for studies that can establish characteristics of the patients who require RAEP and the risk factors (3-6).

It is known that some RAEP cases can be prevented and the risks can be decreased as long as reliable markers are found (7). The aim of this study was to determine the socio-de- mographic and clinical characteristics of patients that required RAEP in the ED of Gazi University Faculty of Medicine Hospital and to identify the medical, institutional, or individual risk factors that led to RAEP, and determine the preventable causes of RAEP.

\section{MATERIALS AND METHODS}

\section{Study design}

This study was performed at Department of Emergency, Gazi University Faculty of Medicine, in which approximately 45,000-55,000 adult patients are admitted to ED each year. For

This study was presented as a poster at the $7^{\text {th }}$ European Society for Emergency Medicine (EuSEM) European Congress on Emergency Medicine, 3-6 October 2012, Antalya, Turkey.

Address for Correspondence: Dr. Abdullah Cüneyt Hocagil, Department of Emergency Medicine, Bülent Ecevit University Faculty of Medicine, Zonguldak, Turkey Phone: +905053544472 e-mail: drhocagil@yahoo.com.tr

Received: 20.10.2014 Accepted: 03.07.2015 • DOI: 10.5152/balkanmedj.2015.15917

Available at www.balkanmedicaljournal.org 
this retrospective study, written approval was taken from the hospital management of Gazi University Faculty of Medicine to get the patients file charts and to use the patient's information.

It was a two-stage study that involved the determination of patients older than 17 years of age who required RAEP in the ED within the time period of one year, the analysis of the hospital records, and a survey of 11 questions that was conducted by telephone.

\section{Formation of the study group}

First, the lists that consisted of the patients who required RAEP in the ED between June 1, 2009 and May 31, 2010 were taken from the hospital information system (AVICENNA; Hospital Information Management System, Ankara, Turkey). The files of these patients were requested from the archive unit in accordance with the procedures and the data were recorded in the study form.

In the second stage of the study, a questionnaire was administered by contacting the patients by telephone. Five questions, all of which had two options for each response as yes and no, were asked. The five questions were: "Were you informed about your disease?", "Was any test performed?", "Were the test results explained to you precisely?", "Was the prescription described?", "Were the emergency conditions under which should come in again explained to you?" Additionally, a question that consisted of the following answers was asked: "the complaints related to readmission to ED didn't cease or recurred", "the complaints increased", "I wasn't instructed to go to a polyclinic", I couldn't reach a polyclinic", "I didn't go to a polyclinic", "I was taken to ED from a polyclinic", "I wasn't satisfied with the policlinic" and "I didn't return with the same complaint". Questions were asked to learn the educational status, marital status, occupation, social environment, and habits of the patients.

\section{Exclusion criteria}

The patients whose files could not be found in the hospital records, whose file information was insufficient, who couldn't be reached by telephone, who refused to provide information by telephone, or who refused to be involved in the study were excluded from the study.

\section{Data collection and processing}

The demographic data, underlying diseases, the complaints at admission, the time of admission and discharge, the procedures that were done in the previous admission, diagnosis, possible conditions that caused readmission, vital signs, the duration of ED stay, and information about the hospitalization to a department and intensive care unit were recorded in the study forms. In patients with complaints of more than one system, the most emphasized complaint in the history and/or the nearest complaint to the diagnosis at the time of discharge were taken as the data.

The relationship between the complaints of the patients that were readmitted and complaints from the previous admission were classified as the same, different, or related. The other complaints that were related to the system and the organ of the previous complaint and the complaints that developed after treatments and interventions that were performed under the first diagnosis were accepted as "related complaints". The final diagnoses at each of the two admissions were classified into three groups as the same, different, or related.

In determining the cause of RAEP, the following criteria were used:

Patient-related causes of RAEP:

1. Leaving the emergency service at his/her own request in spite of the medical recommendations;

2. Although instructed to do so and was presented with the opportunity to go to a policlinic, he/she was not admitted to the relevant policlinic;

3. Not using the prescribed prescription;

4. Readmission to ED for control.

Doctor-related causes of RAEP:

1. Not performing the diagnostic and treatment procedures and the algorithms;

2. Early discharge of the patients from ED;

3. Not providing sufficient information to the patient about: his/her disease, the tests that were performed, the treatment that was provided in ED, the expected situations related to his disease and prescription use, and not encouraging participation in follow-up visits.

4. Not presenting the indications for consultation and hospitalization;

5. The occupational seniority of the doctor.

Disease-related causes of RAEP:

1. RAEP that originates from the expected course of the disease.

System-related causes of RAEP:

1. Unable to hospitalize the patient in a department due to a lack of bad.

2. Not making an appointment at the related policlinic in the early period.

\section{Analysis of data}

Statistical analyses were performed using SPSS 16 (SPSS Inc.; Chicago, IL, USA) statistics program. Descriptive analy- 
ses were performed to analyze the sample as whole. The Chisquared, and Fisher's exact tests were used to explore differences across several variables by the type of discharge from the hospital, age groups and the diagnosis received upon readmission. To perform the statistical analyses, type of discharge from the hospital was separated into four categories: discharge, admission to service//ICU, self-discharge, and death. Age groups were separated into three categories: 17-34, 35-64 and 65 and older and diagnosis received in the readmission was separated into three categories as same diagnosis, different diagnosis and diagnosis related to diagnosis received in the first admission. Here, $p<0.05$ was accepted as statistically significant.

\section{RESULTS}

The study was conducted over a one-year period between June 1, 2009 and May 31, 2010 on a total of 46,800 adult patients admitted to the ED in this period. Seven hundred and seventy-nine $(1.66 \%)$ patients were identified from the hospital record system to require RAEP and 350 of these patients were excluded from the study. A total of 429 patients were included the study (Figure 1).

One hundred and seventy-two patients were aged between 17-34 years, $45.0 \%$ were aged between 35-65 years, and $14.9 \%$ were aged above 65 years. It was found that the patients that required RAEP consisted mostly of the educated pa-

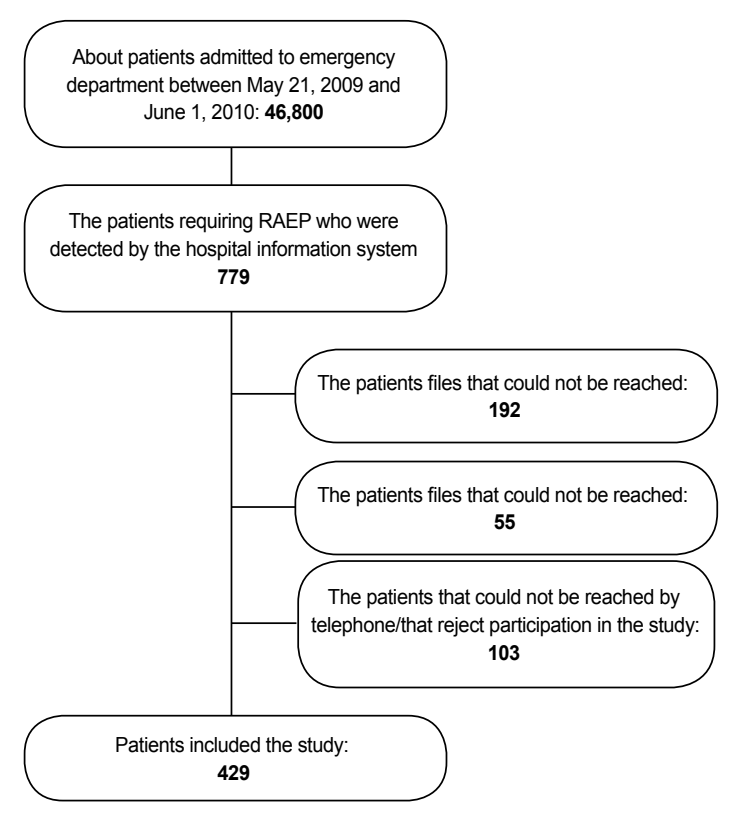

FIG. 1. The flow diagram of the patients in the study (RAEP: readmission in early period) tients, retired patients, and housewives and 15 of them (3.5\%) had no social security. When the social environments of the patients were examined, it was seen that a great majority of them (78.5\%) lived with their family, $8.6 \%$ of them lived alone, and $1.2 \%$ of them lived in a nursing home (Table 1).

While there were no indications in the previous medical history of $48.5 \%$ of the patients ( $n=208$ ), there was malignancy in $12.6 \%$ of them $(\mathrm{n}=54)$. The second most common accompanying comorbidity was hypertension at a rate of $4 \%$.

TABLE 1. Demographic characteristics of patients

\begin{tabular}{|c|c|c|}
\hline & $\mathrm{n}$ & $\%$ \\
\hline \multicolumn{3}{|l|}{ Age groups } \\
\hline $17-34$ & 172 & 40.1 \\
\hline $35-65$ & 193 & 45.0 \\
\hline$>65$ & 64 & 14.9 \\
\hline \multicolumn{3}{|l|}{ Gender } \\
\hline Male & 222 & 51.7 \\
\hline Female & 207 & 48.3 \\
\hline \multicolumn{3}{|l|}{ Education status } \\
\hline University & 132 & 30.8 \\
\hline High school & 116 & 27.0 \\
\hline Primary education & 151 & 35.2 \\
\hline Absent & 30 & 7.0 \\
\hline \multicolumn{3}{|l|}{ Marital status } \\
\hline Married & 263 & 61.3 \\
\hline Single & 166 & 38.7 \\
\hline \multicolumn{3}{|l|}{ Occupations } \\
\hline Retired & 96 & 22.4 \\
\hline Officer & 65 & 15.2 \\
\hline Craftsman & 24 & 5.6 \\
\hline Worker & 56 & 13.1 \\
\hline Housewife & 110 & 25.6 \\
\hline Unemployed & 23 & 5.4 \\
\hline Student & 55 & 12.8 \\
\hline \multicolumn{3}{|l|}{ Social security } \\
\hline Present & 414 & 96.5 \\
\hline Absent & 15 & 3.5 \\
\hline \multicolumn{3}{|l|}{ Social environment } \\
\hline At home with family & 336 & 78.4 \\
\hline Alone & 37 & 8.6 \\
\hline At home with caregiver & 36 & 8.6 \\
\hline At nursing home & 5 & 1.2 \\
\hline Other & 15 & 3.2 \\
\hline \multicolumn{3}{|l|}{ Medical history } \\
\hline Diabetes mellitus & 9 & 2.1 \\
\hline Chronic Obstructive Pulmonary Disease & 9 & 2.1 \\
\hline
\end{tabular}


TABLE 1. Demographic characteristics of patients (Continued)

\begin{tabular}{lcc}
\hline & $\mathrm{n}$ & $\%$ \\
\hline Asthma attack & 5 & 1.2 \\
Coronary artery disease & 7 & 1.6 \\
Hypertension & 17 & 4.0 \\
Chronic renal failure & 2 & 0.5 \\
Congestive heart failure & 2 & 0.5 \\
Malignancy & 54 & 12.6 \\
Hematological diseases & 2 & 0.5 \\
Endocrine diseases & 1 & 0.2 \\
Neurological diseases & 7 & 1.6 \\
Psychiatric disorders & 7 & 1.6 \\
Other & 52 & 12.1 \\
No properties & 208 & 48.5 \\
Multiple & 47 & 11.0 \\
Total & 429 & 100.0 \\
\hline
\end{tabular}

Almost seventy-three percent of the patients $(n=313)$ came back to emergency room with the same complaints as they admitted on the first occasion. There was a statistically significant difference in patient complaints in the re-admission by the diagnosis in the two admissions $(\mathrm{p}<0.001)$ (Table 2). Almost fifty-seven percent of them $(n=178)$ received the same diagnosis during their readmission while $13 \%$ of those who returned to ER with different complaints received the same diagnosis in their readmission; also, $11 \%$ of those who returned to ER with the complaints similar as the first admission received the same diagnosis in their readmission. The most frequent complaint for RAEP was related to the gastrointestinal system (20.8\%), respiratory system $(12.4 \%)$, genitourinary system $(11.9 \%)$, and musculoskeletal system (10.3\%) respectively (Figure 2). The most frequent cause of RAEP was renal colic in 46 patients $(10.7 \%)$ and urticaria in 30 patients $(7.0 \%)$. When the patients were asked the reason for their RAEP, $72.2 \%$ of them indicated that their complaints did not cease, increase, or recur, not allowing time for admission to the policlinic.

In their previous admission, while $59.0 \%$ of the patients stayed in the ED for 1-3 hours, $5.7 \%$ of them were followed-up in ED for more than 24 hours. It was observed that those that had a shorter duration of ED stay in their previous admissions had higher rates of RAEP.

Variation by age group was observed among the duration of stay in ED. Seventy percent of patients age between 1734 remained in ED for 1-3 hours, while $59 \%$ of those aged between 35-65 stayed in the ED for 1-3 hours and only 28\% of those age greater than 65 stayed in ED for 1-3 hours (p value $=<.0001)$ (Table 3).

Of the patients that required RAEP, most of them $(n=303)$ were discharged while $15.0 \%$ were hospitalized in clinics or

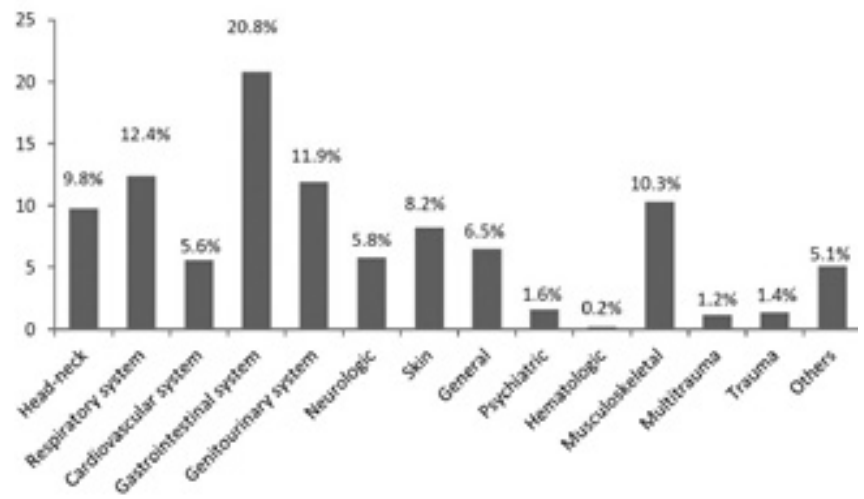

FIG. 2. Distribution the complaints of patients according to the related systems

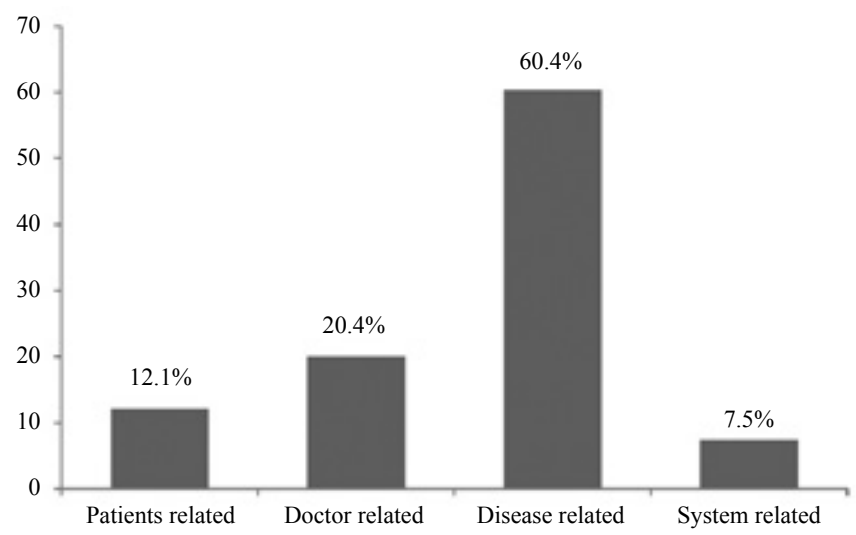

FIG. 3. Distribution of related conditions in readmissions during the early period

in intensive care, $1.2 \%$ died in $\mathrm{ED}$, and $4.0 \%$ left $\mathrm{ED}$ on their own request (Table 4). Variation by age groups were observed among the type of discharge from the emergency room $(\mathrm{p}=0.04)$ (Table 5). Among patients who were hospitalized in clinics or intensive care, half of them were $(n=32)$ between age of 35-64 (Table 5). In four of the five patients that died, there was active malignancy and the final diagnosis in these patients who died was sepsis in four patients and pericardial tamponade in one patient.

In their previous admission, $80.2 \%$ of the patients were evaluated by the resident of the Emergency Medicine Department and $49.9 \%$ of these were first year residents.

It was revealed that $60.4 \%$ of the causes of RAEP were related to the disease, $20.0 \%$ were related to the doctor, $12.1 \%$ were related to the patient and $7.5 \%$ were related to the system (Figure 3). A significant differences were observed. The rate of hospitalization of the patients that required RAEP due to disease related causes ( $85.3 \%$ ) was significantly hig- 
TABLE 2. Patient's complaints in the readmission by the type of diagnosis they received in the readmission

\begin{tabular}{|c|c|c|c|c|c|c|c|}
\hline & \multicolumn{2}{|c|}{ Same diagnosis } & \multicolumn{2}{|c|}{ Different diagnosis } & \multicolumn{2}{|c|}{$\begin{array}{l}\text { Similar diagnosis } \\
\text { as the first admission }\end{array}$} & \multirow[t]{2}{*}{ *p value } \\
\hline & $\mathrm{n}$ & $\%$ & $\mathrm{n}$ & $\%$ & $\mathrm{n}$ & $\%$ & \\
\hline Same complaints & 178 & 56.8 & 67 & 54.0 & 68 & 66.0 & \multirow{4}{*}{$<0.001$} \\
\hline Different complaints & 7 & 3.5 & 36 & 29.1 & 8 & 7.8 & \\
\hline Similar complaints as the first admission & 17 & 0.08 & 21 & 16.9 & 27 & 26.2 & \\
\hline Total & 202 & 100.0 & 124 & 28.9 & 103 & 24.0 & \\
\hline
\end{tabular}

TABLE 3. Distribution of duration of stay in ED by age groups

\begin{tabular}{|c|c|c|c|c|c|c|c|}
\hline \multirow[b]{3}{*}{ Duration of stay in ED } & \multicolumn{6}{|c|}{ Age groups } & \multirow[b]{3}{*}{${ }^{*} \mathrm{p}$ value } \\
\hline & \multicolumn{2}{|c|}{$17-34$} & \multicolumn{2}{|c|}{$35-65$} & \multicolumn{2}{|c|}{$>65$} & \\
\hline & $\mathrm{n}$ & $\%$ & $\mathrm{n}$ & $\%$ & $\mathrm{n}$ & $\%$ & \\
\hline 1-3 hours & 121 & 70.3 & 114 & 59.1 & 18 & 28.1 & \multirow{6}{*}{$<0.001$} \\
\hline 3-6 hours & 35 & 20.3 & 37 & 19.2 & 17 & 26.6 & \\
\hline 6-12 hours & 10 & 5.8 & 19 & 9.8 & 12 & 18.8 & \\
\hline $12-24$ hours & 3 & 1.7 & 9 & 4.7 & 10 & 15.6 & \\
\hline$>24$ hours & 3 & 1.7 & 14 & 7.3 & 7 & 10.9 & \\
\hline Total & 172 & 100.0 & 193 & 100.0 & 64 & 100.0 & \\
\hline
\end{tabular}

ED: emergency department

*p value was obtained by using Chi-square test.

TABLE 4. The type of discharge from emergency department according to the underlying causes of RAEP

\begin{tabular}{lccccccccccc}
\hline & \multicolumn{2}{c}{ Discharge } & \multicolumn{2}{c}{ Service/ICU admission } & \multicolumn{2}{c}{ Self-discharge } & \multicolumn{2}{c}{ Death } & \multicolumn{2}{c}{ Total } \\
Underlying causes of RAEP & $\mathrm{n}$ & $\%$ & $\mathrm{n}$ & $\%$ & $\mathrm{~N}$ & $\%$ & $\mathrm{n}$ & $\%$ & $\mathrm{n}$ & $\%$ & $* \mathrm{p}$ value \\
\hline Disease related & 221 & 85.3 & 29 & 11.2 & 7 & 2.7 & 2 & 0,3 & 259 & 100 & $<0.001$ \\
Doctor related & 59 & 68.6 & 22 & 25.6 & 2 & 2.3 & 3 & 3.5 & 86 & 100 \\
Patient related & 37 & 71.2 & 8 & 15.4 & 7 & 13.5 & 0 & 0 & 52 & 100 \\
System related & 26 & 81.3 & 5 & 15.6 & 1 & 3.1 & 0 & 0 & 32 & 100 \\
Total & 343 & 80.0 & 64 & 14.9 & 17 & 3.9 & 5 & 1.2 & 429 & 100 \\
\hline
\end{tabular}

RAEP: readmission in early period; ICU: Intensive Care Unit

*Chi-square test (Differences arise from causes associated with disease)

TABLE 5. Distribution of age groups and the type of discharge from the emergency department

\begin{tabular}{|c|c|c|c|c|c|c|c|c|c|}
\hline \multirow[b]{2}{*}{ Age groups } & \multicolumn{2}{|c|}{ Discharge } & \multicolumn{2}{|c|}{ Service/ICU admission } & \multicolumn{2}{|c|}{ Leaved on his own request } & \multicolumn{2}{|c|}{ Death } & \multirow[b]{2}{*}{ *p value } \\
\hline & $\mathrm{n}$ & $\%$ & $\mathrm{n}$ & $\%$ & $\mathrm{n}$ & $\%$ & $\mathrm{n}$ & $\%$ & \\
\hline $17-34$ & 149 & 43.4 & 17 & 26.5 & 5 & 29.4 & 1 & 20.0 & 0.04 \\
\hline $35-64$ & 146 & 42.6 & 32 & 50.0 & 11 & 64.7 & 4 & 80.0 & \\
\hline$\geq 65$ & 48 & 14.0 & 15 & 23.4 & 1 & 5.9 & 0 & 0.0 & \\
\hline Total & 343 & 100.0 & 64 & 100.0 & 17 & 100.0 & 5 & 100.0 & \\
\hline
\end{tabular}

ICU: Intensive Care Unit

*p value was obtained by using Fisher's Exact Test.

her than the patients that required RAEP due to other causes $(p=0.001)$ (Table 4). The ratio of patients readmitted to ED due to the inability to schedule an appointment at a policlinic was $6.8 \%$.

\section{DISCUSSION}

It is important for the safety of the patient and the doctor to determine the patients who could possibly return in the early period, 
especially those who could return with a worse clinical condition. The patient group that returned to ED within the first 72 hours was at high risk and should be more thoroughly evaluated (8).

In some studies, it was stated that the ratio of RAEP to ED could be a marker of quality $(9,10)$. However, there is no precise data about which level of RAEP ratios are ideal or an indicator of high quality. In the United States, it was stated that RAEPs constitute approximately $3 \%$ of all admissions to ED (11). When the studies on this subject were examined, it was discovered that the ratio of RAEP to ED within 72 hours is between $0.4 \%$ and $5.4 \%(1,8,12,13)$. The RAEP ratio of $1.66 \%$ in the current study indicates a correlation with these studies.

It was stated that recurrent diseases such as the exacerbation of asthma, chronic pancreatitis, headache, vertigo, cancer pain, and flank pain in urolithiasis constituted $60 \%$ of RAEP cases (14). Hu (15) defined the five most common causes found to be related to the readmissions as chronic obstructive pulmonary disease, benign prostate hypertrophy, urolithiasis, bronchial asthma, and coronary artery disease. In another study, while the otalgia, abdominal pain, complaints of urinary tract infections, seizure, sore throat, and head traumas were other frequent causes of admissions, septicemia, pneumonia, and asthma were the most common diagnoses in return visits (16). Seizure, urinary tract infections, and pneumonia are among the group of diseases with high risk (16). Gill defined the cases that had a high risk of RAEP as mental dysfunctions, genitourinary system diseases (infections 35\%, stone disease $22.5 \%$ ), abdominal pain at a rate of $20.5 \%$, and chest pain at a rate of $16.8 \%$ (3). McCusker et al. (17) determined that the complaints of elderly patients in readmissions originated from the gastrointestinal system $(29.0 \%)$ and respiratory system $(24.7 \%)$. Brewer indicated that the most common complaint that was misdiagnosed is abdominal pain, or epigastric pain. They detected that the actual diagnosis of these patients who were diagnosed with gastritis or gastroenteritis on their first admissions were appendicitis, duodenal ulceration, biliary tract diseases, and ileus (2). In the current study, while gastrointestinal system complaints most frequently caused RAEP in all age groups, the two most common diagnoses were renal colic and urticaria (Figure 2).

In one study, it was revealed that $67 \%$ of all RAEP cases in ED were related to the complaints of the patient in previous admission, $28 \%$ of the patients required RAEP due to a different complaint (18). In another study, the readmission rate with different complaints was $12 \%$ (12). In the current study, $11.9 \%$ of the patients required RAEP due to different complaints. Although most of them presented with the same or a related complaint, it was seen that the rate of different diagnosis was high. Similarly, the rate of hospitalization in patients who required RAEP with a related complaint was found to be higher than the number of patients who required RAEP due to the same or different complaints. These differences may be related to the false diagnosis of the doctor who initially treated the patient, and may also be related to the differences in entries to the International Classification of Diseases (ICD) record system. Both situations demonstrate the importance of careful consideration of the medical history of all patients admitted to the ED, providing detailed information to the patients about the treatment, and the accurate recording of these data.

The common aim in the studies that investigate readmissions in the early period is to prevent or minimize unnecessary readmissions (9). Keith reported that $32.3 \%$ of readmissions result from preventable reasons. They found that $39.6 \%$ of preventable readmissions result from treatment defects, $14.6 \%$ from improper prescription, $20.8 \%$ from presenting insufficient patient education, and $36.5 \%$ from patient incompatibility (9). In another study, they remarked that $15 \%$ of RAEP cases could be preventable through comprehensive patient education (10). In two different studies, it was found that $1 / 3$ of the patient- and disease-related unexpected returns were preventable returns and the patients who were admitted for the second time due to preventable causes were discharged after reevaluation $(3,9)$. It is assumed that most of the doctor-, patient-, and system-related readmissions that were detected in the current study were preventable.

It was shown that RAEP rates are between $8.2 \%$ and $26 \%$ due to errors in medical care in the first admission $(1,5,10,19$ 21). In the studies of $\mathrm{Wu}$, early discharges constituted most of the doctor-related factors, and false diagnosis constituted $3.7 \%$ of them (1). In the study conducted by Hung, the ratio of RAEP related to false diagnosis was $9.0 \%$ (15). In the study of Pierce, the most common doctor-related cause (12\%) was early discharge of the patients (7). They reported that discharge of the patients after the initial evaluation and as soon as the symptoms ceased increased RAEP (22). The necessary treatment should be provided to patients that have been admitted to ED and excess or fewer treatments should be avoided (19). A correlation between the experience of the doctor that evaluated the patient in ED and RAEP was defined (21).

In the study of Liaw et al. (12), regarding patients who were admitted with the same complaints, they found returns related to malpractices to account for $7.8 \%$ and the rate of hospitalization of these patients was $73.7 \%$. In a study of Wu et al. (1), it was found that doctor-related RAEP requires longer duration of hospitalization compared to the other causes related to RAEP. In this study, all of the patients that were misdiagnosed and $72.8 \%$ of the patients that were incorrectly treated were hospitalized. Also in the current study, it was found that the patients who returned due to doctor-related causes were hospitalized in clinics and intensive care units at a higher rate $(25.6 \%)$. 
The most common causes of patient-related RAEP are classified as drug abuse, incompatible patients, anxiety, necessity of records due to legal or other reasons, the request of the family for the reevaluation of the patient, or the individual requirements of the patient and bypassing official procedures (2). Pierce found the main cause of readmissions to be patient-related factors at a rate of $53 \%$. These factors included: leaving the ED in spite of the medical warnings, leaving without being visited by the doctor, anxiety, chronic psychiatric conditions, drug dependency, drug abuse, incompatible patient, malignancy, and social problems. The rate of patient related RAEP was found to be $9.1 \%$ according to Liaw et al. (12) and $14.2 \%$ by Hung et al. (14). In the current study, the patient-related causes of RAEP (12.1\%) were found to include conditions such as not using the prescribed medication, not obeying recommendations at discharge, acting unwillingly to admit to the related specialty, work hours preventing the patient from visiting a polyclinic, leaving the ED in spite of the medical warnings, and feeling the need to ask another doctor's opinion.

In two studies that were conducted, the rates of system related RAEP were found at such low rates as $3 \%$ and $1 \%(19$, 21). However, in the current study, the rate of system-related RAEP was $7.5 \%$. It seems that due to the absence of available beds in the clinic, the discharge of the patients who should be hospitalized in a clinic after being treated in ED for a while and unable to reach polyclinic services sufficiently in the early period are the system-related causes of RAEP in our hospital. Generating hospital criteria for hospitalization and arranging policlinic appointments of the patients at the time of discharge would help to diminish this problem.

The readmission in the early period cases in ED is mostly related to the causes originating from the course of the disease. However, it can also be due to medical or doctor mistakes in a considerable amount. The hospitalization of some patients who required RAEP to clinics or intensive care units, and the presence of patients who died in the ED, support the thought that the patients that require RAEP constitute a high-risk patient group.

Specific studies are needed to determine the causes of avoidable RAEP and consider a solution.

Ethics Committee Approval: Ethics committee approval was received for this study from the ethics committee of Gazi University Faculty of Medicine.

\section{Informed Consent: N/A.}

Peer-review: Externally peer-reviewed.
Author contributions: Concept - F.B., A.C.H., A.D.; Design A.C.H., H.H.; Supervision - F.B., A.C.H., A.D.; Resource - A.C.H., H.K.; Materials - A.C.H., H.H., H.K.; Data Collection \&/or Processing - A.C.H., H.H., A.K., H.K.; Analysis \&/or Interpretation İ.K., A.C.H.; Literature Search - A.C.H., H.H., H.K.; Writing - F.B., A.C.H., H.H., A.K.; Critical Reviews - F.B., A.C.H., A.D.

Conflict of Interest: No conflict of interest was declared by the authors.

Financial Disclosure: The authors declared that this study has received no financial support.

\section{REFERENCES}

1. Wu CL, Wang FT, Chiang YC, Chiu YF, Lin TG, Fu LF, et al. Unplanned Emergency Department Revisits within 72 Hours to a Secondary Teaching Referral Hospital in Taiwan. J Emerg Med 2010;38:512-7. [CrossRef]

2. Sturm JJ, Hirsh DA, Lee EK, Massey R, Weselman B, Simon HK. Practice Characteristics. That Influence Nonurgent Pediatric Emergency Department Utilization. Acad Pediatr 2010;10:70-4. [CrossRef]

3. Martin-Gill C, Reiser RC. Reiser Risk factors for 72-hour admission to the ED. Am J Emerg Med 2004;22:448-53. [CrossRef]

4. $\mathrm{Hu} \mathrm{KW}, \mathrm{Lu} \mathrm{YH}$, Lin HJ, Guo HR, Foo NP. Return unscheduled Emergency Department Visits With and Without Admission Discharge Post. J Emerg Med 2012;43:1110-8. [CrossRef]

5. Nunez S, Hexdall A, Aguirre-Jaime A. Unscheduled returns to the emergency department: an outcome of medical errors? Qual Saf Health Care 2006;15:102-8. [CrossRef]

6. Han CY, Chang W, Lee HL. Unplanned revisits to the emergency department: What emergency department nurses can do? AENJ 2009; 12:178. [CrossRef]

7. Fan JS, Kao WF, Yen DHT, Wang LM, Huang C, Lee CH. Risk factors and prognostic predictors of unexpected intensive care unit admission with in 3 days after ED discharge. Am J Emerg Med 2007;25:1009-14. [CrossRef]

8. Lerman B, Kobernick MS. Return visits to the emergency department. J Emerg Med 1987;5:359-62. [CrossRef]

9. Keith KD, Bocka JJ, Kobernick MS, Krome RL, Ross MA. Emergency department revisits. Ann Emerg Med 1989;18:9648. [CrossRef]

10. Pierce JM, Kellerman AL, Bounces CO. An analysis of shortterm return visits to a public hospital emergency department. Ann Emerg Med 1990;19:752-7. [CrossRef]

11. Gordon JA, An LC, Hayward RA, Williams BC. Initial Emergency Department Diagnosis and Return Visits: Risk Versus Perception. Ann Emerg Med 1998;32:569-73. [CrossRef]

12. Liaw SJ, Bullard MJ, Hu PM, Chen JS, Liao HC. Rates and causes of emergency department revisits within 72 hours. J Formos Med Assoc 1999;98:422-5. 
13. Sklar DP, Crandall CS. In reply. Ann Emerg Med 2008;212:216. [CrossRef]

14. Hung SC, Chew G, Kong CT, Hsiao CT, Liaw JS. Unplanned emergency department revisits within 72 hours. J Taiwan Emerg Med 2004;6:230-8.

15. Hu SC. Analysis of patient revisits to the emergency department. Am J Emerg Med 1992;10:366-70. [CrossRef]

16. Gordon JA, An LC, Hayward RA, Williams BC. Initial Emergency Department Diagnosis and Return Visits: Risk Versus Perception. Ann Emerg Med 1998;32:569-73. [CrossRef]

17. McCusker J, Cardin S, Bellavance F, Belzile E. Return to the emergency department among elders: patterns and predictors. Acad Emer Med 2000;7:249-59. [CrossRef]

18. Adekoya N. Patients seen in emergency departments who had a prior visit with in the previous $72 \mathrm{~h}$-National Hospital Ambula- tory Medical Care Survey 2002. Public Health 2005;119:91498. [CrossRef]

19. Kelly AM, Chirnside AM, Curry CH. An analysis of unscheduled return Visits to an urban emergency department. $N$ Z Med J 1993; 106:334-6.

20. Miro O, Jimenez S, Alsina C, Javier Tovillas-Moran F, Sanchez M, Borras A, et al. Un scheduled revisits in Medical emergency units at the hospital: incidence and related factors. Med Clin (Barc) 1999;112:610-5.

21. Kellermann AL. Clinical emergency medicine, today and tomorrow. Ann Emerg Med 1995;25:235-8. [CrossRef]

22. Sklar DP, Crandall CS, Loeliger E, Edmunds K, Paul I, Helitzer DL. Unanticipated death after discharge home from the emergency department. Ann Emerg Med 2007;49:735-45. [CrossRef] 